\title{
Comparison of mannitol and methacholine to predict exercise-induced bronchoconstriction and a clinical diagnosis of asthma
}

\author{
Sandra D Anderson*1, Brett Charlton², John M Weiler ${ }^{3}$, Sara Nichols ${ }^{4}$, \\ Sheldon L Spector ${ }^{5}$, David S Pearlman ${ }^{6}$ and A305 Study Group ${ }^{6}$
}

Address: ${ }^{1}$ Department of Respiratory and Sleep Medicine, Royal Prince Alfred Hospital, Missenden Road, Camperdown, NSW 2050, Australia, 2Pharmaxis Ltd, 2/10 Rodborough Rd, Frenchs Forest, NSW 2086, Australia, ${ }^{3}$ CompleWare Corporation, PO Box 3090, Iowa City, IA 52244-3090 and University of Iowa, Iowa City, IA 52242, USA, ${ }^{4}$ CompleWare Corporation, PO Box 3090, Iowa City, IA 52244-3090, USA, ${ }^{5}$ California Allergy and Asthma Medical Group, 11645 Wilshire Blvd., Ste. 1155, Los Angeles, CA 90025, USA and ${ }^{6}$ Colorado Allergy \& Asthma Centers, PC, 125 Rampart Way, Suite 150, Denver, CO 80230-6405, USA

Email: Sandra D Anderson* - sandya@med.usyd.edu.au; Brett Charlton - Brett.Charlton@pharmaxis.com.au;

John M Weiler - jweiler@compleware.com; Sara Nichols - snichols@compleware.com; Sheldon L Spector - spector@calallergy.com;

David S Pearlman - DS.Pearlman@coloradoallergy.com; A305 Study Group - sandya@med.usyd.edu.au

* Corresponding author

Published: 23 January 2009

Respiratory Research 2009, 10:4 doi:10.1186/1465-9921-10-4

This article is available from: http://respiratory-research.com/content//0/1/4

(c) 2009 Anderson et al; licensee BioMed Central Ltd.

This is an Open Access article distributed under the terms of the Creative Commons Attribution License (http://creativecommons.org/licenses/by/2.0), which permits unrestricted use, distribution, and reproduction in any medium, provided the original work is properly cited.

\begin{abstract}
Background: Asthma can be difficult to diagnose, but bronchial provocation with methacholine, exercise or mannitol is helpful when used to identify bronchial hyperresponsiveness (BHR), a key feature of the disease. The utility of these tests in subjects with signs and symptoms of asthma but without a clear diagnosis has not been investigated. We investigated the sensitivity and specificity of mannitol to identify exercise-induced bronchoconstriction (EIB) as a manifestation of BHR; compared this with methacholine; and compared the sensitivity and specificity of mannitol and methacholine for a clinician diagnosis of asthma.
\end{abstract}

Methods: 509 people (6-50 yr) were enrolled, $78 \%$ were atopic, median FEV, $92.5 \%$ predicted, and a low NAEPPII asthma score of I.2. Subjects with symptoms of seasonal allergy were excluded. BHR to exercise was defined as a $\geq 10 \%$ fall in FEV, on at least one of two tests, to methacholine a $\mathrm{PC}_{20} \leq 16 \mathrm{mg} / \mathrm{ml}$ and to mannitol a $15 \%$ fall in $\mathrm{FEV}$, at $\leq 635 \mathrm{mg}$ or a $10 \%$ fall between doses. The clinician diagnosis of asthma was made on examination, history, skin tests, questionnaire and response to exercise but they were blind to the mannitol and methacholine results.

Results: Mannitol and methacholine were therapeutically equivalent to identify ElB, a clinician diagnosis of asthma, and prevalence of BHR. The sensitivity/specificity of mannitol to identify EIB was $59 \% / 65 \%$ and for methacholine it was $56 \% / 69 \%$. The BHR was mild. Mean EIB \% fall in FEV in subjects positive to exercise was 19\%, (SD 9.2), mannitol PD ${ }_{15} 158(\mathrm{Cl}: 129,193)$ $\mathrm{mg}$, and methacholine $\mathrm{PC}_{20} 2.1(\mathrm{Cl}: 1.7,2.6) \mathrm{mg} / \mathrm{ml}$. The prevalence of BHR was the same: for exercise (43.5\%), mannitol (44.8\%), and methacholine $(41.6 \%$ ) with a test agreement between $62 \& 69 \%$. The sensitivity and specificity for a clinician diagnosis of asthma was $56 \% / 73 \%$ for mannitol and $5 / \% / 75 \%$ for methacholine. The sensitivity increased to $73 \%$ and $72 \%$ for mannitol and methacholine when two exercise tests were positive.

Conclusion: In this group with normal $\mathrm{FEV}_{1}$, mild symptoms, and mild BHR, the sensitivity and specificity for both mannitol and methacholine to identify EIB and a clinician diagnosis of asthma were equivalent, but lower than previously documented in welldefined populations.

Trial registration: This was a multi-center trial comprising 25 sites across the United States of America. (NCT0025229). 


\section{Background}

Asthma can be difficult to diagnose and no single symptom or test should be used in isolation to make the diagnosis. A correct diagnosis is important in order for patients to receive appropriate therapy [1]. Because bronchial hyperresponsiveness (BHR) is a hallmark of asthma, bronchial provocation challenge tests (BPTs) with a variety of agents have been used to assist in its diagnosis [2-4].

Methacholine is a commonly used agent, delivered as a wet aerosol. Methacholine acts directly on acetylcholine receptors on smooth muscle causing contraction and airway narrowing. Methacholine has been reported to have a high sensitivity to identify BHR and a negative test is often used to exclude asthma $[5,6]$.

Provocation tests that use indirect stimuli (e.g. exercise and mannitol) have a high specificity for asthma [7] causing smooth muscle contraction by release of endogenous mediators including prostaglandins, leukotrienes, and histamine $[8,9]$. Evaporative water loss occurs in conditioning the inspired air and causes exercise induced bronchoconstriction (EIB) by inflammatory mediators of mast cell origin $[10,11]$. Exercise is generally recognised as having a low sensitivity to identify BHR; EIB is consistent with a diagnosis of asthma [12] and responds to chronic treatment with inhaled corticosteroids (ICS) and other drugs used in the treatment of asthma [13-15].

A dry powder of mannitol has been developed as an indirect $\mathrm{BPT}[16]$ and is available as a standardized test kit. The test kit contains pre-filled mannitol capsules in escalating doses and a hand-held dry powder inhaler device. Safety and efficacy of mannitol as a BPT were established in a large Phase III clinical trial in patients with asthma and in healthy subjects [7].

The usefulness of mannitol as a BPT in subjects with signs and symptoms of asthma but no clear diagnosis has not been investigated previously. The aim was to study a large population of subjects to compare the sensitivity and specificity of mannitol with methacholine to detect EIB as a manifestation of BHR and to identify a clinician diagnosis of asthma.

\section{Subjects: inclusion criteria}

Subjects aged $6-50$ years (BMI < 35) with signs and symptoms suggestive of asthma according to the National Institute of Health (NIH) Questionnaire [17] but without a firm diagnosis of asthma or an exclusion of the diagnosis of asthma (e.g. had an equivocal diagnosis of asthma or had been referred for further investigation of asthma-type symptoms) were included. Subjects had at least Step 1 symptoms according to the NAEPPII asthma severity grading (symptoms $\leq 2$ times per week; asymptomatic between exacerbations; exacerbations of only a few hours to a few days; and night time symptoms of $\leq 2$ times per month). They were required to have an $\mathrm{FEV}_{1} \geq 70 \%$ of the predicted value at the Screening Visit $[18,19]$.

Subjects were excluded from participating in this study if they: had any known other pulmonary disease; had smoked more than 1 cigarette per week within the past year or had $\mathrm{a} \geq 10$ pack year smoking history; had a respiratory tract infection within the previous 4 weeks; had been skin test positive to aeroallergens that were present in the environment during the time of enrolment and reported worsening of symptoms when exposed to these aeroallergens during the study; had been diagnosed at Screening Visit as definitively having asthma (95 to 100\% likelihood) or not having asthma ( 0 to $<5 \%$ likelihood); had clinically significantly abnormal chest x-ray or ECG; or had failed to observe washout of medications that would interfere with BPT (including, but not limited to, no use of corticosteroids within 4 weeks of the Screening Visit).

\section{Methods}

The protocol was approved by a central institutional review board. Each subject or parent gave informed consent in writing. The study consisted of 5 visits to the clinic. On the Screening Visit the following were assessed: eligibility; demographic data; medical history; medications; spirometry with reversibility (following $360 \mathrm{mcg}$ of albuterol); allergy skin test reactivity to common allergens (positive test taken as $3 \mathrm{~mm}$ wheal). The NIH NAEPPII questionnaire was answered and a score was assigned [20]. Vital signs including blood pressure, heart rate, and respiratory rate were measured in the sitting position and an ECG performed. Based on this information, a respiratory physician assigned one of 6 diagnoses at this visit on the basis of the likelihood of asthma as follows: asthma is extremely likely or definite $(95 \%-100 \%$ likelihood); asthma is very likely ( 72.5 to $<95 \%)$; asthma is probable ( 50 to $<72.5 \%$ ); asthma is possible $(27.5$ to $<50 \%$ ); asthma is unlikely but cannot be excluded ( 5 to $27.5 \%$ ); and asthma is very unlikely $(0-<5 \%)$. Those with 5 to $95 \%$ likelihood were included in the study.

Visit 2 occurred 1-4 days after Visit 1 and within 2 hrs of the time of Screening. Adverse events, medications, and withholding times were reviewed (Table 1), and spirometry measured to confirm values on the screening day. This was followed by a brief physical examination. Exercise was performed with vital signs being measured before and after exercise. At Visit 3, the procedures were the same as Visit 2 and occurred within 1-4 days. At Visit 4, adverse events and medications were reviewed, withholding times were checked, and spirometry was performed to confirm $\mathrm{FEV}_{1}$ was within $15 \%$ of Visit 1 . The challenge agent was 
Table I: Medications and other factors that may decrease bronchial hyperresponsiveness and their required withholding periods

\begin{tabular}{|c|c|c|}
\hline & FACTOR & Withholding Period \\
\hline \multirow[t]{5}{*}{ Inhaled agents } & $\begin{array}{l}\text { Short acting bronchodilators (isoproterenol, isoetharine, metaproterenol, albuterol, } \\
\text { levalbuterol, terbutaline) (e.g. Proventil }{ }^{\circledR} \text { or Ventolin }{ }^{\circledR} \text { ) }\end{array}$ & $8 \mathrm{hr}$ \\
\hline & Inhaled anticholinergics or combination products (e.g. Atrovent ${ }^{\circledR}$ or Combivent ${ }^{\circledR}$ ) & I week \\
\hline & Medium acting bronchodilators (ipratropium) & I week \\
\hline & Long acting inhaled bronchodilators (salmeterol, formoterol) (e.g. Serevent ${ }^{\circledR}$ or Foradil ${ }^{\circledR}$ ) & 2 weeks \\
\hline & Inhaled corticosteroid/long acting inhaled bronchodilator combination (e.g. Advair ${ }^{\circledR}$ ) & 4 weeks \\
\hline \multirow[t]{5}{*}{ Oral bronchodilators } & Theophylline & $24 \mathrm{hr}$ \\
\hline & Intermediate theophylline & $48 \mathrm{hr}$ \\
\hline & Long acting theophylline & $48 \mathrm{hr}$ \\
\hline & Standard $\beta$-agonist tablets & $24 \mathrm{hr}$ \\
\hline & Long acting $\beta$-agonist tablets & $48 \mathrm{hr}$ \\
\hline Corticosteroids & There is no washout for topical steroids applied to skin unless they are high potency steroids & 4 weeks \\
\hline \multirow[t]{7}{*}{ Other medications } & Hydroxyzine, cetirizine (and other antihistamines) & $72 \mathrm{hr}$ \\
\hline & Tiotropium bromide & $72 \mathrm{hr}$ \\
\hline & Nasals steroids & I week \\
\hline & $\beta$-blockers & I week \\
\hline & Cromolyn sodium & 2 weeks \\
\hline & Nedocromil & 2 weeks \\
\hline & Leukotriene modifiers & 6 weeks \\
\hline Foods & Coffee, tea, cola drinks, chocolate (caffeinated foods) & $12 \mathrm{hr}$ \\
\hline \multicolumn{2}{|c|}{ Strenuous exercise or exposure to cold air to a level that would be expected to interfere with challenges } & $12 \mathrm{hr}$ \\
\hline Tobacco & & $6 \mathrm{hr}$ \\
\hline
\end{tabular}

either mannitol or methacholine, and the choice was randomly determined. The time of the test was documented for each challenge. Vital signs were measured in the sitting position before and after the challenge test. Cough and pulse oximetry were recorded during mannitol challenges. Full spirometry was measured before and at 15 minutes after completion of the mannitol challenge with $\mathrm{FEV}_{1}$ only being performed after each dose. ECG was performed before and after mannitol challenge. Visit 5 was a repeat of the procedures of Visit 4 with the reciprocal challenge being administered (either mannitol or metha- choline). A respiratory physician then assigned one of the diagnoses of likelihood of asthma evaluated at the Screening Visit, above. The NAEPII asthma severity grading score was also re-evaluated at Visit 5 but not necessarily by the same physician.

\section{Bronchial provocation tests}

Exercise challenge

Exercise was performed by running on a motorised treadmill whilst breathing medical grade dry air $\left(20-25^{\circ} \mathrm{C}\right)$ from a Douglas Bag [14]. Briefly exercise was ramped up 
over two minutes to $80-90 \%$ predicted heart rate (220age) and then sustained for 6 minutes. The highest $\mathrm{FEV}_{1}$ was measured before and at 5, 10, 15 and 30 minutes after exercise. The $\%$ fall in $\mathrm{FEV}_{1}$ was calculated by subtracting the lowest value recorded after exercise (best of two acceptable attempts at each time point) from the value measured immediately before exercise and expressing it as a percentage of the pre exercise value. A subject was deemed positive if there was a fall of $\geq 10 \%$ in $\mathrm{FEV}_{1}$ at one time point $[2,3]$ on at least one of the two exercise challenges.

\section{Mannitol challenge}

The mannitol test was carried out as per the standard laboratory protocol for this challenge test using the commercially available mannitol test kit (known as Aridol ${ }^{\mathrm{TM}}$ or Osmohale $^{\mathrm{TM}}$ Pharmaxis Ltd, AUS) [7]. The FEV 1 was measured 60 seconds after each mannitol dose $(0,5,10,20,40$, $80,160,160,160 \mathrm{mg})$. The subjects were asked to exhale completely before taking a controlled deep inspiration from the device and to hold their breath for 5 seconds then exhale through their mouth before removal of the nose clip. Sixty seconds after inhalation of the $0 \mathrm{mg}$ capsule the $\mathrm{FEV}_{1}$ was measured in duplicate. The highest of these values was taken as the baseline $\mathrm{FEV}_{1}$ and was used to calculate the target $\mathrm{FEV}_{1}$ value that indicated a $15 \%$ fall in response to the mannitol challenge. The test result expressed is a $P D_{15}$.

The procedure outlined above for the $0 \mathrm{mg}$ capsule was repeated for each dose step until a $15 \%$ fall in $\mathrm{FEV}_{1}$ was achieved (or a 10\% fall between consecutive doses) or the cumulative dose of $635 \mathrm{mg}$ had been administered.

\section{Methacholine}

Methacholine (Provocholine ${ }^{\mathrm{TM}}$, Methapharm CA) was delivered from a nebulizer (DeVilbiss model 646) by the dosimeter method [2]. The concentrations were: 0.0312 , $0.0625,0.125,0.25,0.5,1,2,4,8,16 \mathrm{mg} / \mathrm{mL}$. Each concentration required five inhalations from functional residual capacity to total lung capacity. Spirometry was performed within 3 minutes. The response to methacholine was expressed as the concentration required to provoke a $20 \%$ fall in $\mathrm{FEV}_{1}$ from the pre-challenge value $\left(\mathrm{PC}_{20}\right)$.

\section{Bronchodilator}

On Visit 1 a dose of 360-400 mcg of albuterol (salbutamol) was administered and the $\mathrm{FEV}_{1}$ measured between 15 and 30 minutes. A positive test was defined as a $12 \%$ increase in $\mathrm{FEV}_{1}$ above the baseline value.

\section{Statistical testing}

Results were expressed using univariate statistics including means, standard deviations, ranges, and medians.
Mannitol and methacholine responses were log transformed for calculation of the geometric means. The analysis plan specified a test of non-inferiority to be achieved if the lower 95\% credible limit for the adverse-event-freeratio $\left(1-\mathrm{AER}_{\text {mannitol }}\right) /\left(1-\mathrm{AER}_{\text {methacholine }}\right)$ exceeded 0.80 .

\section{Analysis}

The sensitivity and specificity of a mannitol positive test (defined as $\geq 15 \%$ fall in $\mathrm{FEV}_{1} \leq 635 \mathrm{mg}$ or a $\geq 10 \%$ fall in $\mathrm{FEV}_{1}$ between consecutive doses) and a methacholine positive test (defined as $\mathrm{PC}_{20} \mathrm{FEV}_{1} \leq 16 \mathrm{mg} / \mathrm{ml}$ ) with respect to EIB (defined as $\geq 10 \%, 15 \%$ or $20 \%$ fall in $\mathrm{FEV}_{1}$ after a standardized treadmill run) and with respect to a clinician's diagnosis of asthma at Visit 5 were calculated. Additional analyses were performed excluding those with a mannitol test taking longer than 35 minutes because the osmotic gradient will not progressively increase if the time between doses is prolonged.

\section{Safety data}

Vital signs (including blood pressure, heart rate, and respiratory rate) using the intent-to-treat population (ITTP, $\mathrm{n}$ $=391$ ) and their changes during challenge tests are described. The adverse events were tabulated following each challenge test. The per-protocol population (PPP, $n$ $=375$ ) included all subjects with no major protocol violations who completed all of the required challenge tests, including methacholine and mannitol challenges.

In the protocol cough was identified as an adverse event if it prevented the challenge from being completed in which case it was documented as severe at the time of testing.

\section{Blinding}

A respiratory physician was to make the Clinician diagnosis at the final visit (Visit 5) with access to the data on the exercise challenges, history, examination, skin tests, and $\mathrm{FEV}_{1}$ reversibility but not the mannitol and methacholine challenge test result. Site staff members performing mannitol and methacholine challenges were not provided with other diagnostic information about the subject to assure that there was no bias in the performance of these tests. Mannitol and methacholine challenges were given in a restricted randomization scheme that produced equal numbers of each order.

To accomplish proper blinding, the mannitol and methacholine challenge team did not have access to the electronic case report form (eCRF) or to other physiological data. Similarly, other site personnel did not have access to the mannitol and methacholine challenge data. Mannitol and methacholine challenge data were able to be reviewed by the Data Manager at CompleWare Inc but they were only provided to the Sponsor (Pharmaxis Ltd) at the end of the study. 


\section{Results}

The disposition of the subjects is given in Figure 1. There were 16 people in the ITTP who were not included in the PPP. The data are given for the PPP unless otherwise stated because it represents the results for all the subjects who performed all the tests. The age distribution for 375 subjects in the PPP are presented in Table 2. The characteristics of the subjects are summarised in Table 3 . There were 96 children and 279 adults (> 18 years); $51.5 \%$ female; 76.3\% Caucasian, 8.3\% Hispanic and 8.5\% Black; with near-normal baseline spirometry; with low NAEPPII asthma score of 1.2 (SD 0.5 ); $78 \%$ atopic; and $7.5 \%$ responding positively to a bronchodilator. Of the 375 , 145 were considered by the respiratory physician to have a $50 \%$ or more likelihood of having asthma at Visit 1.

There were $163(43.5 \%)$ subjects who had a positive response to exercise (Exc+) with $\mathrm{a} \geq 10 \%$ fall in FEV1 on at least one test; 119 recording this on the first exercise test with 66 of these 119 recording $\mathrm{a} \geq 15 \%$ fall in FEV1. There were $168(44.8 \%)$ subjects with a positive test to mannitol (Mann+). Of these, 109 achieved a 15\% fall in $635 \mathrm{mg}$ and the remaining achieved a positive test by a $10 \%$ fall in FEV1 between consecutive doses. Seventy three percent achieved this response within the first 6 doses of mannitol ( $\leq 315 \mathrm{mg})$. There were $156(41.6 \%)$ with a positive test to methacholine (Mech+) with a PC20 $\leq 16 \mathrm{mg} / \mathrm{ml}$, and $26 \%$ achieved this response within the first 6 concentrations $(\leq 1 \mathrm{mg} / \mathrm{ml})$ being delivered. The percentile values and median data for the positive responses are given in Table 4.

Sensitivity and specificity of mannitol and methacholine to identify a subject with different levels of severity of EIB is given in Table 5. There was no significant difference between mannitol and methacholine to identify EIB; however, these agents did not necessarily identify the same people and the agreement between the mannitol and methacholine test results was $69 \%$. Agreement for mannitol and exercise was $62 \%$ and for methacholine and exercise was $63 \%$. The relationship between the reactivity to mannitol expressed as log RDR and the reactivity to exercise expressed as the maximum \% fall in $\mathrm{FEV}_{1}$ was significant but not strong ( $\mathrm{r}=0.256, \mathrm{p}<0.001, \mathrm{n}=312)$. Maximum \% fall in $\mathrm{FEV}_{1}$ to mannitol in relation to methacholine $(\mathrm{r}=0.41 \mathrm{p}<0.0001)$ in those positive and negative to exercise is illustrated in Figure 2. Forty-six (29\%) people had a fall $\geq 30 \%$ in $\mathrm{FEV}_{1}$ after methacholine, 2 (1.2\%) after mannitol and 25 (15.3\%) after exercise. The mean maximum \% fall (SD) in $\mathrm{FEV}_{1}$ after those with a positive methacholine challenge was $27.7 \% \pm(8.2)$ and after a positive mannitol challenge was $16.1 \% \pm(5.6)$. The fall after mannitol was $19.2 \% \pm(4)$ excluding those who were positive due to a $10 \%$ fall between doses, and this was the same as the fall after exercise $19.1 \%$ (9.4). Sensi- tivity and specificity of mannitol and methacholine to identify Exc+ $10 \%$ in relation to symptoms score is summarised in Table 6.

Mannitol had a sensitivity of $67 \%$ to identify a Mech+ PC20 of $\leq 16,68 \%$ for $\leq 12$, and $68 \%$ for $\leq 8 \mathrm{mg} / \mathrm{ml}$ and a sensitivity of $77 \%$ to identify $\leq 4 \mathrm{mg} / \mathrm{ml}$ and $83 \%$ to identify $\leq 2 \mathrm{mg} / \mathrm{ml}$. Methacholine had a sensitivity of $62 \%$ for identifying a Mann+ response. An Exc $+10 \%$ on the first test had a sensitivity of $62 \%$ to identify Exc $+10 \%$ on the second test. The receiver operator curves for mannitol and methacholine in relation to identifying EIB is illustrated in Figure 3 and are almost identical for mannitol and methacholine. The negative and positive predictive values for mannitol and methacholine were close generally differing by 0.01 or less. Similarly the negative $(0.64$ and 0.65 ) and positive likelihood ratios (1.71 and 1.79) were similar for mannitol and methacholine respectively.

There were $28(7.5 \%)$ subjects in the per protocol population who reversed at least $12 \%$ after a beta ${ }_{2}$ agonist. This small group showed a sensitivity of mannitol and methacholine to identify EIB of $68.4 \%$ and $73.7 \%$ and a specificity of $44.4 \%$ and $55.5 \%$ respectively.

Sensitivity and specificity for mannitol and methacholine to identify a $10 \%$ fall after exercise in children and a clinical diagnosis at Visit 5 is given in Table 7. Of the 375 PPP, there were 240 (64\%) identified as having a clinical diagnosis of asthma at Visit 5 (ClinDx5+) and $48 \%$ of these had a likelihood of asthma (see definitions above) greater than $50 \%$ assigned at Visit 1 . Fifteen percent of the subjects who received a clinical diagnosis of asthma were negative to all three challenges. Of the 135 who did not receive a clinical diagnosis of asthma at Visit 5 (ClinDx5), $78 \%$ had a likelihood of asthma of less than $50 \%$ assigned at Visit 1. Sensitivity and specificity of mannitol to predict ClinDx5+ was 55\% and 73\%. The sensitivity for mannitol rose to $73 \%$ when ClinDx5+ was associated with two Exc+ $10 \%$ tests. The comparable sensitivity and specificity for methacholine $\left(\mathrm{PC}_{20} \leq 16 \mathrm{mg} / \mathrm{ml}\right)$ was $51 \%$ and $75 \%$ and sensitivity rose to $72 \%$ when ClinDx $5+$ was associated with two Exc $+10 \%$ tests.

The positive and negative predictive values for mannitol for a ClinDx $5+$ were $79 \%$ and $48 \%$ and for methacholine they were $78 \%$ and $46 \%$. There were 106 subjects negative to mannitol, 118 negative to methacholine and 92 negative to exercise who were given a clinician diagnosis of asthma at Visit 5. When the subjects who took longer than $35 \mathrm{~min}$ for a mannitol challenge were excluded, the sensitivity of mannitol to identify a 95\% risk of having asthma as judged by the clinician was $76 \%$. For methacholine this equivalent value was $67 \%$. 


\begin{tabular}{|c|c|}
\hline $\begin{array}{l}\text { Enrolled by site \& } \\
\text { recorded in } \\
\text { electronic } \\
\text { case report form } \\
\quad \mathrm{n}=510\end{array}$ & $\begin{array}{l}\text { Excluded from Safety, Efficacy Analyses: } \quad \mathrm{n}=74 \\
\text { - Inclusion/Exclusion: Elevated BMI (9) } \\
\text { - Inclusion/Exclusion: Active Allergies (2) } \\
\text { - Inclusion/Exclusion: Smoking (2) } \\
\text { - Inclusion/Exclusion: Asthma Very Likely or Very Unlikely (19) } \\
\text { - Inclusion/Exclusion: Cannot perform spirometry (5) }\end{array}$ \\
\hline & $\begin{array}{l}\text { - Inclusion/Exclusion: Baseline } \mathrm{FEV}_{1}<70 \% \text { Predicted (9) } \\
\text { - Withdrew Consent/Lost to Follow-up (15) } \\
\text { - Excess FEV } \text { Eariability (1) }_{\text {- }} \text { Adverse Event (2) } \\
\text { - Enrolment Closed (7) }\end{array}$ \\
\hline $\begin{array}{l}\text { Safety: } \\
\text { Intent-to-Treat, } \\
\text { Per Protocol \& } \\
\text { Safety } \\
\text { Populations } \\
\mathrm{n}=436\end{array}$ & \multirow{2}{*}{$\begin{array}{l}\text { Excluded from Intent-to-Treat Analysis: } \mathrm{n}=45 \\
\text { - Included in P+ but not in Per Protocol population because } \\
\text { exercise challenge was inadequate and both exercise } \\
\text { challenges were negative (29) } \\
\text { - Withdrew consent }(5) \\
\text { - Took prohibited drug (2) } \\
\text { - Excess FEV variability (1) } \\
\text { - Adverse Event (4) } \\
\text { - Enrolment closed (1) } \\
\text { - Inadequate spirometry (2) } \\
\text { - Inclusion/Exclusion: Asthma Very Likely (1) }\end{array}$} \\
\hline & \\
\hline $\begin{array}{l}\text { Intent-to-Treat: } \\
\text { Intent-to-Treat \& } \\
\text { Per Protocol } \\
\text { Populations } \\
\mathrm{n}=391\end{array}$ & $\begin{array}{l}\text { Intent-to-Treat Plus Population: } \mathrm{n}=420 \\
\text { - Intent-to-Treat (391) } \\
\text { - Missed portion of exercise challenge, both negative (3) } \\
\text { - Inadequate exercise challenge, both negative (26) }\end{array}$ \\
\hline & $\begin{array}{l}\text { Excluded from Per Protocol Analysis: } \\
\text { - Withdrew consent (5) } \\
\text { - Methacholine doses missed (5) } \\
\text { - Methacholine doses given out of order (1) } \\
\text { - } \text { Aridol challenge not completed (4) } \\
\text { - Inclusion/Exclusion: Antihistamine taken (1) }\end{array}$ \\
\hline $\begin{array}{l}\text { Per Protocol: } \\
\text { Per Protocol } \\
\text { Populations } \\
\quad n=375\end{array}$ & $\begin{array}{l}\text { Per Protocol Plus Population: } \quad \mathrm{n}=404 \\
\text { - Per Protocol (375) } \\
\text { - Missed portion of exercise challenge, both negative (3) } \\
\text { - Inadequate exercise challenge, both negative (26) }\end{array}$ \\
\hline
\end{tabular}

Figure I

Subject disposition. 
Table 2: Demographics: Age distribution in the intent-to-treat, in the excluded and safety, and in the per-protocol populations.

\begin{tabular}{|c|c|c|c|c|c|c|}
\hline \multirow[b]{2}{*}{ Age } & \multicolumn{2}{|c|}{ Intent-to-Treat } & \multicolumn{2}{|c|}{ Excluded and Safety } & \multicolumn{2}{|c|}{ Per-Protocol } \\
\hline & Number & Percent & Number & Percent & Number & Percent \\
\hline Total & 391 & & 509 & & 375 & \\
\hline $6-7$ & 6 & $1.5 \%$ & 9 & $1.8 \%$ & 6 & $1.6 \%$ \\
\hline $8-9$ & 7 & $1.8 \%$ & 11 & $2.2 \%$ & 7 & $1.9 \%$ \\
\hline $10-11$ & 20 & $5.1 \%$ & 25 & $4.9 \%$ & 19 & $5.1 \%$ \\
\hline $12-15$ & 38 & $9.7 \%$ & 48 & $9.4 \%$ & 36 & $9.6 \%$ \\
\hline $16-18$ & 44 & $11.3 \%$ & 57 & $11.2 \%$ & 43 & $11.5 \%$ \\
\hline $19-24$ & 113 & $28.9 \%$ & 135 & $26.5 \%$ & 108 & $28.8 \%$ \\
\hline $25-30$ & 69 & $17.6 \%$ & 84 & $16.5 \%$ & 68 & $18.1 \%$ \\
\hline $31-35$ & 28 & $7.2 \%$ & 44 & $8.6 \%$ & 25 & $6.7 \%$ \\
\hline $36-40$ & 31 & $7.9 \%$ & 44 & $8.6 \%$ & 29 & $7.7 \%$ \\
\hline $4 I-45$ & 19 & $4.9 \%$ & 25 & $4.9 \%$ & 19 & $5.1 \%$ \\
\hline $46-50$ & 16 & $4.1 \%$ & 27 & $5.3 \%$ & 15 & $4.0 \%$ \\
\hline
\end{tabular}

The time to perform a positive mannitol test was significantly shorter than a positive methacholine test by approximately $25 \mathrm{~min}$ (19.9 $\mathrm{min}$ [SE 0.9] vs $44.5 \mathrm{~min}$ [SE 1.4]). In those Mech+ only it was $48.3 \mathrm{~min}$ (SE 1.7) and for those Mann+ only it was $19.2 \mathrm{~min}$ (SE 1.3).

Time for recovery of $\mathrm{FEV}_{1}$ to $95 \%$ of baseline was similar for all tests. Mannitol was 21.6 min (SD 9.0) vs. methacholine $21.06 \mathrm{~min}$ ( $\mathrm{SD}$ 6.96); the maximum time for recovery on the two exercise tests was $22.9 \mathrm{~min}$ (SD 13.7). Median time for recovery after mannitol and methacholine was 19 min (interquartile range 17-24).
Sensitivity and specificity for methacholine to identify EIB were considerably less consistent across the centres than for mannitol. The between centre standard deviation for the log odds ratio for methacholine and mannitol was respectively 1.26 vs. 0.32 for sensitivity $(p<0.02)$ and 0.68 vs 0.47 ( $p=$ NS) for specificity. Thus there was significantly less variation in sensitivity of mannitol to identify EIB between centres compared with methacholine.

The skin test results for the wide variety of allergies are summarised in Table 8 for the per protocol population. The percentage of subjects positive to one or more skin tests for those Exc+ was $42.6 \%$, for Mann+ it was $47.1 \%$

Table 3: Anthropometric data, forced expiratory volume in one second, and smoking history in the per protocol population.

\begin{tabular}{lcccccccc}
\hline & Age (yr) & BMI & FEV (L) & \% Pred FEV & Post BD FEV (L) & Pack Yrs & Ht (cm) & Wt (kg) \\
\hline Mean & 24.3 & 24.4 & 3.32 & $93.6 \%$ & 3.48 & 2.9 & 167.4 & 69.2 \\
\hline SD & 10.2 & 4.5 & 0.82 & 10.0 & 0.87 & 2.8 & 13.1 & 18.4 \\
\hline Range & $6-50$ & $13.4-34.9$ & $1.15-5.62$ & $63.7-140.1$ & $1.29-5.92$ & $0-9$ & $118-204.5$ & $20-135.2$ \\
\hline Median & 22 & 24.1 & 3.24 & 93.3 & 3.32 & 2.5 & 167.6 & 69 \\
\hline
\end{tabular}


Table 4: Percentile and geometric mean values for bronchial provocation tests as well as maximum $\%$ fall for subjects with positive exercise challenges.

\begin{tabular}{|c|c|c|c|c|}
\hline & \multicolumn{3}{|c|}{ Percentiles } & \multirow[b]{2}{*}{ Geomean $(95 \% \mathrm{Cl})$} \\
\hline & 25th & 50th & 75th & \\
\hline Mann $^{+} P_{15}(\mathrm{mg})$ & 72 & 234 & 374 & $158(129,193)$ \\
\hline $\mathrm{Mech}^{+} \mathrm{PC}_{20}(\mathrm{mg} / \mathrm{ml})$ & 0.84 & 2.98 & 6.53 & $2.12(1.7,2.64)$ \\
\hline Exc ${ }^{+} \%$ Fall & $23.6 \%$ & $15.5 \%$ & $12.4 \%$ & $19.1 \%(9.25)^{*}$ \\
\hline
\end{tabular}

*Mean (SD)

and for Mech+ it was $41.8 \%$. It was higher in those achieving a ClinDx $5+63.0 \%$.

During mannitol challenges, frequency of cough was monitored in 419 subjects. Of these 391 had cough (93\%) with 204 having occasional cough (49\%) that did not interfere with the challenge, 178 frequent cough $(42 \%)$ that delayed the administration of the next dose and 9 severe cough $(2.1 \%)$ that caused the challenge to be stopped and an adverse event to be recorded.

Vital signs changed as expected, with increased in systolic and diastolic blood pressure, heart rate, and respiratory rate associated with both exercise challenges. Trivial increases in blood pressure were seen associated with mannitol and methacholine challenges. Oxygen saturation did not change appreciably with mannitol challenge and only 3 subjects had $>3 \%$ reduction. Heart rate increased slightly after mannitol challenge and decreased

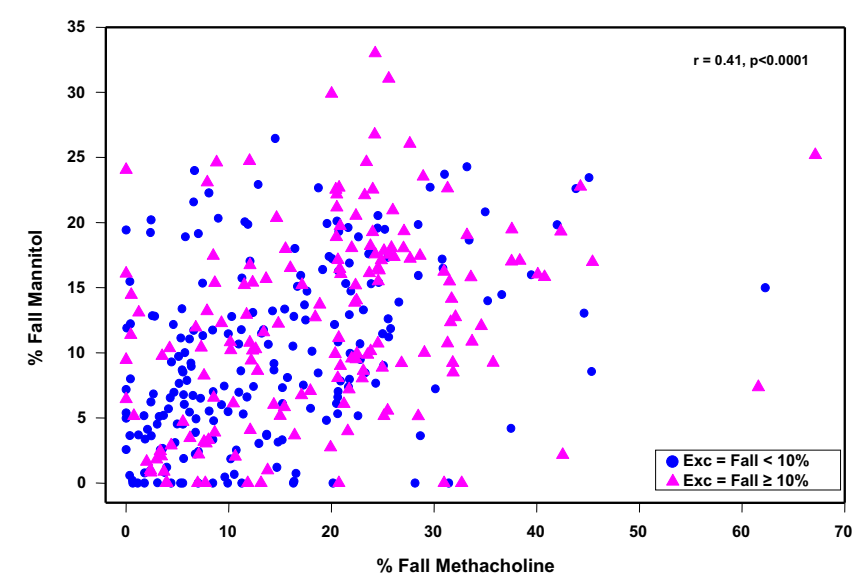

Figure 2

The maximum percentage fall in FEV, for mannitol and methacholine in subjects in the per-protocol population. slightly after methacholine challenge. Respiratory rate was also largely unchanged with both mannitol and methacholine challenge.

\section{Adverse events}

All adverse events which commenced after the challenges were reported by MedDRA System Organ Class and Preferred Term and tabulated (Table 9) There were more adverse events on mannitol compared with methacholine 130 vs 89 . The distribution across range of severity of events was the same. There were 62 moderate adverse events on mannitol and 35 on methacholine, with 9 severe ones on mannitol and 3 on methacholine. There were no serious adverse events for any of the challenge tests. Mannitol was non-inferior to methacholine in the sense that the proportion of subjects who did not experience adverse events in the mannitol challenge was at least $80 \%$ of the proportion who did not experience adverse events in the methacholine challenge (92.9\%) as per the statistical analysis plan.

\section{Discussion}

In these subjects with very mild symptoms suggestive of asthma and good lung function, sensitivity and specificity were equivalent for mannitol and methacholine to identify EIB and a clinical diagnosis of asthma. There were no serious adverse events associated with the tests and both were generally well tolerated.

Mannitol sensitivity to identify EIB was lower than that previously reported in subjects with a definite diagnosis of asthma $[21,22]$. The lower sensitivity of mannitol to identify EIB reported here is consistent with the mild EIB (50\% of subjects had falls in $\mathrm{FEV}_{1} \leq 15 \%$ ) documented in this group who did not have a definite diagnosis of asthma. The \% fall in $\mathrm{FEV}_{1}$ in the asthmatics reported by Brannan [21] was $40 \pm 19 \%$ (SD) and by Munoz [22] it was $37 \% \pm$ $16 \%$ (SD). In the study of Holzer [23] a $\mathrm{PD}_{15}$ to mannitol had a sensitivity of $83 \%$ to identify EIB in a group of athletes with a $25.4 \% \pm 15 \%$ (SD) fall in $\mathrm{FEV}_{1}$ after eucapnic voluntary hyperpnea, a surrogate challenge for EIB. 
Table 5: Sensitivity and specificity of challenge at different cut points for a positive test.

\begin{tabular}{|c|c|c|c|c|}
\hline Exercise Positive Cut-Points - \% fall from baseline & & $10 \%$ & $15 \%$ & $20 \%$ \\
\hline Mannitol & Sensitivity & 58.6 & 69.4 & 78.6 \\
\hline $\mathrm{n}=372$ & Specificity & 65.2 & 62.0 & 60.8 \\
\hline Excluding those with challenge $>35 \mathrm{~min}$ & Sensitivity & 64.1 & 75.3 & 82.7 \\
\hline$n=319$ & Specificity & 59.9 & 57.0 & 55.4 \\
\hline Methacholine $16 \mathrm{mg} / \mathrm{ml}$ & Sensitivity & 55.2 & 67.4 & 80.3 \\
\hline $\mathrm{n}=375$ & Specificity & 68.9 & 66.1 & 65.2 \\
\hline
\end{tabular}

The sensitivity of mannitol to identify a Exc+ 20\% fall in $\mathrm{FEV}_{1}$ was $>80 \%$ when those with a prolonged mannitol test time were excluded. Sensitivity of the mannitol to detect a Exc $+10 \%$ fall was also $>80 \%$ in those with an asthma symptom severity score of 2 rather than 1 , although the numbers with this score were smaller.

Sensitivity and specificity of methacholine and mannitol for a clinical diagnosis of asthma was equivalent in this study, but the values were lower than those reported in well-defined populations of asthmatic and healthy subjects [7] and similar to those reported for epidemiological studies [24-26]. In the children less than 18 yrs, however, mannitol had a $18.5 \%$ higher specificity $(81.4 \%$ vs $62.9 \%$ ) for identifying a clinical diagnosis of asthma and a $10 \%$ lower sensitivity (60.1\% vs $70 \%$ ) to identify EIB compared with methacholine.

This lower than expected sensitivity for mannitol and methacholine to identify EIB or a clinical diagnosis may be explained by the relatively unusual nature of this group of subjects who would not have qualified either for a clinical study on asthmatic subjects or a study on healthy subjects. The exclusion criteria required that the subjects not be symptomatic to the allergens to which they demonstrated atopy at the time of the study. This too is unusual and may affect mast cell number and IgE status. There was a lack of agreement between the clinical diagnosis and response to the challenge tests in $27 \%$ of the subjects; $15 \%$ of subjects given a diagnosis of asthma were negative to all three challenge tests and $12 \%$ with two or more positive challenge tests were deemed not to have an asthma diagnosis at Visit 5 . The dose of mannitol $\left(\mathrm{PD}_{15}\right)$ or concentration of methacholine $\left(\mathrm{PC}_{20}\right)$ in those who were positive in this study was consistent with the values reported previously in clinically recognised asthmatics not taking inhaled corticosteroids $[27,28]$.

The prevalence of BHR identified by the three tests differed by only $3.2 \%$ (from $41.6 \%$ to $44.8 \%$ ). This suggests that the cut-off points used to define BHR were appropriate. Further, the range of severity of BHR was similar for all the tests with $50 \%$ being in the mild range for mannitol and exercise and $75 \%$ in the mild range for methacholine [2,29]. However it was not always the same subject responsive to all the BPTs and only $17.9 \%$ of subjects were positive to all three challenge tests. This probably reflects the natural variability of the test responses in people with mild BHR and intermittent symptoms.

Some long-held beliefs about methacholine were not upheld by the results of this study. Methacholine did not

Table 6: Sensitivity and specificity to identify exercise-induced bronchoconstriction (EIB) in relation to the asthma severity score.

\begin{tabular}{|c|c|c|c|c|c|c|c|c|c|}
\hline \multirow[b]{3}{*}{ Asthma Severity Score } & & \multicolumn{8}{|c|}{ NAEPPII } \\
\hline & & \multicolumn{4}{|c|}{ Visit I } & \multicolumn{4}{|c|}{ Visit 5} \\
\hline & & 0 & 1 & 2 & 3 & 0 & I & 2 & 3 \\
\hline & $\mathrm{N}$ mann $=$ & 0 & 308 & 47 & 17 & 13 & 294 & 48 & 15 \\
\hline & $\mathrm{N}$ mech $=$ & 0 & 310 & 48 & 17 & 14 & 296 & 48 & 15 \\
\hline Mannitol & Sensitivity & & 56.6 & 75.0 & 60.0 & 50.0 & 55.1 & 78.3 & 66.7 \\
\hline $635 \mathrm{mg}$ & Specificity & & 69.2 & 48.4 & 42.9 & 72.7 & 67.7 & 56.0 & 16.7 \\
\hline Methacholine & Sensitivity & & 54.7 & 62.5 & 50.0 & 0.0 & 56.3 & 56.5 & 44.4 \\
\hline $16 \mathrm{mg} / \mathrm{ml}$ & Specificity & & 72.8 & 46.8 & 71.4 & 66.7 & 70.8 & 56.0 & 66.7 \\
\hline
\end{tabular}




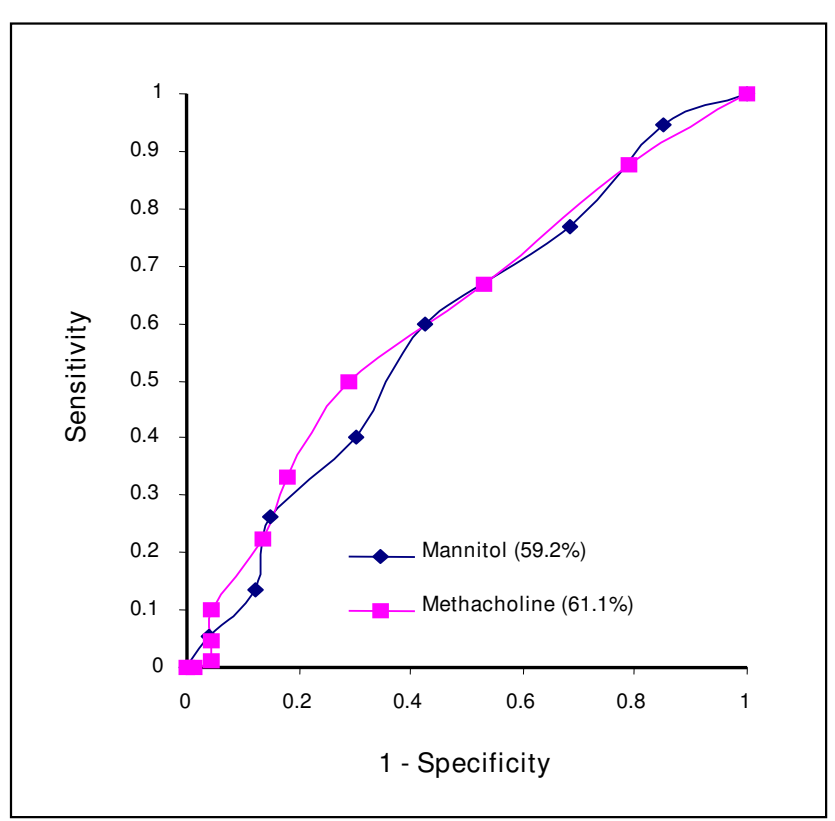

Figure 3

The receiver operating curve for mannitol and methacholine to identify exercise-induced bronchoconstriction defined as $\geq 10 \%$ fall in FEV, from baseline at one time point after exercise on at least one of two exercise tests.

have a higher sensitivity than exercise and mannitol to identify BHR in this population, and the prevalence of BHR was similar for all tests. Methacholine did not have a high negative predictive value for a clinical diagnosis of asthma. There were 118 subjects negative to methacholine who were given a diagnosis of asthma at Visit 5 . It was also not uncommon for methacholine to miss EIB, and 73 of the 163 subjects (45\%) positive to exercise were negative to methacholine, confirming previous findings in young people with good lung function [30]. The sensitivity of a positive response to the first exercise test to predict a positive response to the second test $(62 \%)$ was the same as the sensitivity of mannitol and methacholine to predict at least one positive test to exercise. This low sensitivity probably relates to the variability in the mild response to exercise, particularly in those without symptoms of allergy at the time of testing. By performing a second test, an extra 44 people were identified as having EIB. Care was taken in
Table 7: Children < I8 yrs $(n=|| \mid 5)$. Per protocol population

\begin{tabular}{llcc}
\hline "Gold Standard" & & I0\% Ex+ & ClinDx5+ $^{+}$ \\
\hline Mannitol & Sensitivity & 60.1 & 63.2 \\
& Specificity & 58.5 & 81.4 \\
\hline Methacholine $16 \mathrm{mg} / \mathrm{ml}$ & Sensitivity & 70.0 & 66.2 \\
& Specificity & 54.5 & 62.9 \\
\hline
\end{tabular}

this study to minimise the potential for variability, and there was good overall agreement between the two exercise test results; however, this was primarily due to the number of negative exercise tests.

Only one exercise test and one time point of $\geq 10 \%$ was required to be the 'gold' standard used for BHR. This criterion may be interpreted by some investigators as not strict enough because of the variability of the response to exercise. However the value for sensitivity of mannitol to identify EIB was relatively unchanged (59.8\% vs $58.3 \%$ ) when only those subjects with two time points on one exercise challenge were $\geq 10 \%$, or one time point was greater than $\geq 15 \%$, were included in the analysis. The value for sensitivity for methacholine however rose from $55.3 \%$ to $63.1 \%$ applying the same criteria.

There were $7.5 \%$ of subjects with a positive response to bronchodilator at baseline who were not excluded at entry on the basis of having a > 95\% chance of having asthma, presumably as the other evidence was not supportive. This group of 28 showed a higher value for sensitivity of mannitol (68.4\% vs 59\%) and methacholine ( $73.7 \%$ vs $56 \%$ ) to identify EIB when compared with the entire population.

Cockcroft [31] has found that methacholine sensitivity to identify BHR of $4 \mathrm{mg} / \mathrm{ml}$ or more is lower using the dosimeter method compared with the tidal breathing method. The dosimeter method used here is one recommended in the American Thoracic Society guidelines that categorize BHR between $4-16 \mathrm{mg} / \mathrm{ml}$ as borderline [2], is in common use, and delivery of the aerosol by this method involves a similar inspired breathing pattern as the mannitol with which it was being compared. We challenged to $16 \mathrm{mg} / \mathrm{ml}$ and, on the basis of the Cockcroft

Table 8: The frequency of positive skin tests $(>3 \mathrm{~mm}$ wheal) to a variety of allergens in the per protocol population $(\mathrm{n}=375)$.

\begin{tabular}{lcccccccccc}
\hline & Cat & Cockroach & Dog & Grass & House Dust Mites & Mold & *Cedar & Rag weed & Other Weeds & Trees \\
\hline Positive & 153 & 48 & 75 & 180 & 175 & 99 & 56 & 106 & 126 \\
Tests done & 363 & 299 & 363 & 336 & 347 & 363 & 145 & 298 & 146 \\
\% Positive & 42.1 & 16.1 & 20.7 & 53.6 & 50.4 & 27.3 & 38.6 & 35.6 & 323 & 328 \\
\hline
\end{tabular}

*Mountain Cedar 
Table 9: Adverse events following bronchial provocation and those not related to challenge in the safety population.

\begin{tabular}{|c|c|c|c|c|c|c|}
\hline System Organ Class & Preferred Term & Ist Exc\# & 2nd Exc & Mann\# & Meth\# & NCR\# \\
\hline $\mathrm{n}$ & & 435 & 429 & 419 & 420 & 436 \\
\hline I.I All & & $25(8 \%)$ & $21(7 \%)$ & $130(4 \mid \%)$ & $89(28 \%)$ & $49(16 \%)$ \\
\hline \multirow[t]{2}{*}{ Cardiac Disorders } & Class Totals & I (5\%) & 0 & $6(27 \%)$ & $13(59 \%)$ & $2(9 \%)$ \\
\hline & Dizziness & 1 & & 5 & 13 & 0 \\
\hline \multirow[t]{3}{*}{ Gastrointestinal disorders } & Class Totals & I (5\%) & $\mathrm{I}(5 \%)$ & 14 (70\%) & 0 & $4(20 \%)$ \\
\hline & Nausea & & 1 & 5 & & I \\
\hline & Retching & 1 & & 4 & & \\
\hline \multirow{3}{*}{$\begin{array}{l}\text { General disorders and administration site } \\
\text { concerns }\end{array}$} & Class Totals & I (4\%) & 0 & $24(86 \%)$ & $3(11 \%)$ & 0 \\
\hline & Burning sensation mucosal & & & 9 & & \\
\hline & Feeling jittery & & & 6 & 2 & \\
\hline \multirow[t]{2}{*}{ Nervous system disorders } & Class Totals & $4(20 \%)$ & $2(10 \%)$ & $6(30 \%)$ & $4(20 \%)$ & $4(20 \%)$ \\
\hline & Headache & 2 & 1 & 5 & 4 & 4 \\
\hline \multirow[t]{10}{*}{ Respiratory, thoracic and mediastinal disorders } & Class Totals & $12(6 \%)$ & $11(6 \%)$ & $73(39 \%)$ & $66(36 \%)$ & $23(12 \%)$ \\
\hline & Chest discomfort & 3 & 1 & 13 & 18 & I \\
\hline & Cough & 2 & 1 & 9 & 8 & 4 \\
\hline & Dyspnoea & 4 & 3 & 12 & 22 & I \\
\hline & Nasal congestion & & & 1 & 4 & 3 \\
\hline & Pharyngolaryngeal pain & 1 & & 11 & 1 & I \\
\hline & Reversible airways obstruction & & 1 & 3 & 2 & \\
\hline & Rhinitis & & & 3 & 1 & 1 \\
\hline & Rhinorrhea & 2 & & 8 & & 1 \\
\hline & Wheezing & & 1 & 6 & 7 & I \\
\hline
\end{tabular}

\#Exc = Exercise; Mann = Mannitol; Meth = Methacholine; NCR = not challenge related

observation, this may be equivalent to $8 \mathrm{mg} / \mathrm{ml}$ on the tidal breathing method. $\mathrm{A} \mathrm{PC}_{20}$ of $>8 \mathrm{mg} / \mathrm{ml}$ is the value for normality illustrated in the 2007 GINA guidelines [32] and stated by the British Thoracic Society [33].

This study included steroid naïve subjects who were considered to have a greater than $5 \%$ and less than $95 \%$ prob- ability of having asthma at entry based on spirometry, response to bronchodilator, symptoms, history and skin tests. The clinical value in comparing different diagnostic tools, such as the challenge tests used here, cannot really be judged because there is no gold standard test for the diagnosis of asthma. The strategy used here for a 'gold standard' for the diagnosis of asthma was to have a respi- 
ratory physician assign a diagnosis at Visit 5 on the basis of having all the information (including the exercise test results) except the results of the methacholine and mannitol tests. The information available was likely to be more than most clinicians would have available at assessment and thus as close to a clinical gold standard as one is likely to find. There was good agreement $(71.6 \%)$ with the exercise test result and ClinDx5+ diagnosis of asthma with only 14 subjects positive to exercise being considered not to have asthma (ClinDx5-). This supports the fact that BHR to exercise, i.e. EIB, is accepted by clinicians as consistent with a diagnosis of asthma. The agreement between a ClinDx5 diagnosis and the methacholine result was $59.6 \%$ and mannitol was $61.8 \%$.

In the Phase 3 study on mannitol, in subjects with known asthma and healthy subjects without asthma, the specificity and sensitivity of mannitol to identify a clinical diagnosis of asthma was $59.8 \%$ and $95.2 \%$ and it was $88.7 \%$ and $95 \%$ when those with a negative mannitol test being treated with inhaled corticosteroids were excluded [7]. In this study in subjects with symptoms but without a definite diagnosis of asthma at entry mannitol had a sensitivity and specificity of $56 \%$ and $73 \%$ and this was no different to methacholine $51 \%$ and $75 \%$.

In conclusion, mannitol and methacholine provided therapeutic equivalence to identify BHR, EIB, and a clinical diagnosis of asthma in a group of subjects suspected of having asthma but without a clear diagnosis. While mannitol has potential to replace other challenges for BPT, any of these tests can provide specific information and insight regarding mechanism in a particular patient.

\section{Competing interests}

SDA is the inventor of the mannitol test however the intellectual property is owned by her employer, the Sydney South West Area Health Service. SDA has not received any fees personally from Pharmaxis. SDA has undertaken research studies that were funded by Pharmaxis. She is a shareholder in Pharmaxis but holds no options. She is likely to benefit from royalties in the future.

BC is an employee and a shareholder of Pharmaxis Ltd.

JW is the President of, and is a shareholder in, CompleWare Corporation. CompleWare received a fee from Pharmaxis Ltd. for services in carrying out the clinical trial.

$\mathrm{SN}$ is the statistician employed by CompleWare and carried out the statistical analysis.

SS has received an honorarium from the sponsor of the trial (Pharmaxis Ltd) for chairing a pre-meeting seminar at the AAAAI conference and received a research grant for study participation from Pharmaxis.

DSP participated in the study through Colorado Allergy and Asthma Centers PC, which received a research grant for study participation from Pharmaxis Ltd.

There are no other competing interests or conflicts of interest.

\section{Authors' contributions}

$\mathrm{BC}, \mathrm{JW}$, and SDA designed the study (after consultation with the FDA). CompleWare (which employs JW and SN) ran the clinical trial and the data acquisition, and wrote the report on which this paper is based. SN was the statistician for CompleWare. SS and DP were principal investigators who presented abstracts of the work at academic society meetings. All authors contributed suggestions and have approved the final version of the paper. SDA wrote the paper and prepared it for publication and made the decision to submit it to Respiratory Research.

\section{Acknowledgements \\ The A305 Study Group - Principal Investigators:}

Homer Boushey, University of California, CA; Thomas Casale, Creighton University Allergy Division, Creighton University Medical Center, NE; Linda Ford, The Asthma and Allergy Center, P.C., NE; Leon Greos, Colorado Allergy \& Asthma Centers, PC, CO; Phillip Halverson, Clinical Research Institute, MN; Frank Hampel, Central Texas Health Research, TX; Phillip Korenblat, The Clinical Research Center, MO; Craig LaForce, North Carolina Clinical Research, NC; Anne-Marie Irani, Children's Medical Center, VA; Jonathon Matz, Chesapeake Medical Center, MD; Anjuli Nayak, Sneeze, Wheeze \& Itch Associates, LLC, IL; Nancy Ostrum, Allergy \& Asthma Medical Group and Research Center, CA; David Pearlman, Colorado Allergy and Asthma Centers, PC, CO; Andrew Pedinoff, Princeton Center for Clinical Research, NJ; Bruce Prenner, Allergy Associates Medical Group, Inc., CA; Paul Qaqundah, Pediatric Care Medical Group, Inc. CA; Javier Quesada, West Coast Clinical Trials, CA; Paul Ratner, Sylvana Research Associates, PA, TX; Kenneth Rundell, Keith J. O'Neil Center for Healthy Families, Marywood University, PA; Gail Shapiro, A.S.T.H.M.A., Inc., WA; Christine Sorkness, Allergy and Asthma Clinical Research, Wl; Sheldon Spector, California Allergy and Asthma Medical Group, CA; Ricardo Tan, California Allergy and Asthma, Palmdale, CA; Steven Weinstein, Allergy and Asthma Specialists, Medical Group and Research Center, CA; Robert Ziering, Allergy and Immunology Medical Group, CA;

This study was a Phase III clinical trial study funded by Pharmaxis Ltd, NSW Australia 2086. Dr. Brett Charlton of Pharmaxis Ltd was involved in designing the study and identifying the statistics used in the analysis.

\section{References}

I. Expert Panel Report: Update on Selected Topics 2002: National Asthma Education and Prevention Program. National Institutes of Health, National Heart, Lung and Blood Institute, 2003. NIH publication no. 02-5074. 2003.

2. Crapo RO, Casaburi R, Coates AL, Enright PL, Hankinson JL, Irvin CG, Maclntyre NR, McKay RT, Wanger JS, Anderson SD, Cockcroft DW, Fish JE, Sterk PJ: Guidelines for methacholine and exercise challenge testing - 1999. Am J Respir Crit Care Med 2000, 161:309-329. 
3. Sterk PJ, Fabbri LM, Quanjer PH, Cockcroft DW, O'Byrne PM, Anderson SD, Juniper EF, Malo J-L: Airway responsiveness: Standardized challenge testing with pharmacological, physical and sensitizing stimuli in adults. Eur Respir J Suppl 1993, 16:53-83.

4. Van Schoor J, Pauwels R, Joos G: Indirect bronchial hyperresponsiveness: the coming of age of a specific group of bronchial challenges. Clin Exp Allergy 2005, 35(3):250-261.

5. Cockcroft DW: How best to measure airway responsiveness. Am J Respir Crit Care Med 200I, 163:15I4-I5I5.

6. O'Byrne PM, Zamel N: Airway challenges with inhaled constrictor mediators. In Provocation Testing in Clinical Practice Volume 5. Edited by: Spector SL. New York: Marcel Dekker; 1995:3 I I-324.

7. Brannan JD, Anderson SD, Perry CP, Freed-Martens R, Lassig AR, Charlton $B$ : The safety and efficacy of inhaled dry powder mannitol as a bronchial provocation test for airway hyperresponsiveness: a phase 3 comparison study with hypertonic (4.5\%) saline. Respir Res 2005, 6( I 44): I 44.

8. Brannan JD, Gulliksson M, Anderson SD, Chew N, Kumlin M: Evidence of mast cell activation and leukotriene release after mannitol inhalation. Eur Respir J 2003, 22(3):49I-496.

9. Brannan JD, Gulliksson M, Anderson SD, Chew N, Seale JP, Kumlin M: Inhibition of mast cell $\mathbf{P G D}_{2}$ release protects against mannitol-induced airway narrowing. Eur Respir J 2006, 27:944-950.

10. O'Sullivan S, Roquet A, Dahlén B, Larsen F, Eklund A, Kumlin M, O'Byrne PM, Dahlén S-E: Evidence for mast cell activation during exercise-induced bronchoconstriction. Eur Respir J 1998, 1 2:345-350.

II. Reiss TF, Hill JB, Harman E, Zhang J, Tanaka WK, Bronsky E, Guerreiro $D$, Hendeles $L$ : Increased urinary excretion of $\mathrm{LTE}_{4}$ after exercise and attenuation of exercise-induced bronchospasm by montelukast, a cysteinyl leukotriene receptor antagonist. Thorax 1997, 52(12): 1030-1035.

12. Avital A, Springer C, Bar-Yishay E, Godfrey S: Adenosine, methacholine, and exercise challenges in children with asthma or paediatric chronic obstructive pulmonary disease. Thorax 1995, 50:5II-516.

13. Tan RA, Spector SL: Exercise-induced asthma: diagnosis and management. Ann Allergy Asthma Immunol 2002, 89(3):226-235.

14. Weiler JM, Nathan RA, Rupp NT, Kalberg CJ, Emmett A, Dorinsky PM: Effect of fluticasone/salmeterol administered via a single device on exercise-induced bronchospasm in patients with persistent asthma. Ann Allergy Asthma Immunol 2005, 94:65-72.

15. Pearlman DS, van Adelsberg J, Philip G, Tilles SA, Busse W, Hendeles L, Loeys T, Dass SB, Reiss TF: Onset and duration of protection against exercise-induced bronchoconstriction by a single oral dose of montelukast. Ann Allergy Asthma Immunol 2006, 97( I):98-104.

16. Anderson SD, Brannan J, Spring J, Spalding N, Rodwell LT, Chan K, Gonda I, Walsh A, Clark AR: A new method for bronchial-provocation testing in asthmatic subjects using a dry powder of mannitol. Am J Respir Crit Care Med 1997, 1 56:758-765.

17. National Heart Lung and Blood Institute: Guidelines for the Diagnosis and Management of Asthma NIH. 1997.

18. Polgar G, Promadhat V: Pulmonary Function Testing in Children: Techniques and Standards. Philadelphia: W.B. Saunders Co; 1971.

19. Crapo RO, Morris AH, Gardner RM: Reference spirometric values using techniques and equipment that meet ATS recommendations. Am Rev Respir Dis 198I, I 23(6):659-664.

20. National Institute of Health: Guidelines for the Diagnosis and Management of Asthma. In National Institutes of Health, National Heart, Lung and Blood Institute Bethesda MD NHLBI/WHO workshop report Publication No 08-405I; 2007.

21. Brannan JD, Koskela H, Anderson SD, Chew N: Responsiveness to mannitol in asthmatic subjects with exercise- and hyperventilation-induced asthma. Am J Respir Crit Care Med 1998, I 58(4): I I 20-I I 26.

22. Munoz PA, Gomez FP, Manrique HA, Roca J, Barbera JA, Young IH, Anderson SD, Rodriguez-Roisin R: Pulmonary gas exchange response to exercise- and mannitol- induced bronchoconstriction in mild asthma. J Appl Physiol 2008, 105(5): | 477-1485.

23. Holzer K, Anderson SD, Chan H-K, Douglass J: Mannitol as a challenge test to identify exercise-induced bronchoconstriction in elite athletes. Am J Respir Crit Care Med 2003, 167(4):534-547.
24. Riedler J, Reade T, Dalton M, Holst DI, Robertson CF: Hypertonic saline challenge in an epidemiological survey of asthma in children. Am J Respir Crit Care Med 1994, 150:1632-1639.

25. Pattemore PK, Asher MI, Harrison AC, Mitchell EA, Rea HH, Stewart AW: Ethnic differences in prevalence of asthma symptoms and bronchial hyperresponsiveness in New Zealand schoolchildren. Thorax 1989, 44(3): 168-176.

26. Salome CM, Peat JK, Britton WJ, Woolcock AJ: Bronchial hyperresponsiveness in two populations of Australian schoolchildren. I. Relation to respiratory symptoms and diagnosed asthma. Clin Allergy 1987, 17:27I-28I.

27. Porsbjerg C, Brannan JD, Anderson SD, Backer V: Relationship between airway responsiveness to mannitol and to methacholine and markers of airway inflammation, peak flow variability and quality of life in asthma patients. Clin Exp Allergy 2008, 38(I):43-50.

28. Koskela H, Hyvärinen L, Brannan JD, Chan H-K, Anderson SD: Sensitivity and validity of three bronchial provocation tests to demonstrate the effect of inhaled corticosteroids in asthma. Chest 2003, I 24(4): |34|-1349.

29. Anderson SD, Brannan JD: Methods for 'indirect' challenge tests including exercise, eucapnic voluntary hyperpnea and hypertonic aerosols. Clin Rev Allergy Immunol 2003, 24(I):27-54.

30. Holzer K, Anderson SD, Douglass J: Exercise in elite summer athletes: Challenges for diagnosis. J Allergy Clin Immunol 2002, I I 0(3):374-380.

31. Cockcroft DW, Davis BE: The bronchoprotective effect of inhaling methacholine by using total lung capacity inspirations has a marked influence on the interpretation of the test result. J Allergy Clin Immunol 2006, I I 7(6): I 244- I248.

32. Global Initiative for Asthma. Revised 2007. Global strategy for asthma and management and prevention N. H. National Institutes of Health, Lung and Blood Institute, editor. NHLBIIWHO workshop report :16-19 [http://www.ginasthma.org]. Medical Communication Resources, Inc, Bethesda, Maryland

33. British Guideline on the Management of Asthma. Thorax 2008, 63(Suppl 4):ivl-iv12I.
Publish with Bio Med Central and every scientist can read your work free of charge

"BioMed Central will be the most significant development for disseminating the results of biomedical research in our lifetime. "

Sir Paul Nurse, Cancer Research UK

Your research papers will be:

- available free of charge to the entire biomedical community

- peer reviewed and published immediately upon acceptance

- cited in PubMed and archived on PubMed Central

- yours - you keep the copyright

Submit your manuscript here:

http://www.biomedcentral.com/info/publishing_adv.asp
BioMedcentral 